\title{
PRODUZIR MAIS (E MELHOR): UMA QUESTÃO DE SOBREVIVÊNCIA?
}

Dennis Herszkowicz

Nem os mais criativos roteiristas de cinema poderiam imaginar um cenário parecido com o que vivemos em 2020. A pandemia provocou uma revolução sem precedentes na economia e na sociedade e trouxe um elemento de insegurança e incerteza a quase todos os aspectos da vida. No entanto, vivermos em um mundo com tecnologia nos permitiu adaptar muitas das atividades cotidianas ao mundo virtual. Ou seja, o trabalho, a escola, a consulta médica, o happy hour com os amigos, entre tantas outras atividades, continuaram a acontecer, mas a uma tela de distância.

A nova realidade escancarou a necessidade de nos tornarmos indivíduos multitarefa 24 horas por dia. Otimizar a nossa eficiência em tudo o que fazemos, seja nas rotinas domésticas, no estudo ou no trabalho remoto, se tornou fundamental, já que as escalas de horários passaram a se confundir e a ganhar interrupções constantes. Buscar o equilíbrio entre a nossa produtividade e o nosso bem-estar virou um desafio. 
A produção é o resultado, ou seja, um dado sobre o que foi produzido por um determinado período de tempo. A produção tem mais relação com o que deve ser feito do que com como deve ser feito.

Já a produtividade está relacionada ao desempenho, ou seja, como o processo e as pessoas chegam até a essa entrega. É um conceito que requer planejamento, organização, estratégias, estruturas e ferramentas que permitem uma aprimoração do resultado final por essa soma de fatores que ocasionaram a otimização da tarefa.

Mesmo fora do ambiente empresarial, pensar neste conceito de melhor utilização dos recursos é fundamental para a melhoria dos nossos padrões e qualidade de vida. Então, é necessário que nos adaptemos a uma nova realidade, uma nova rotina, que deve incluir cuidados pessoais que irão implicar no nosso desempenho de tarefas do dia a dia. Isso passa pelas horas adequadas de sono, alimentação saudável, atividades físicas e programação do tempo que iremos gastar com cada atividade.

Já para o mercedo eorporativo, a बdeptação "forçade" que estamos passendo em tempos de pendemia deve deixar um importente legados a lição de que as emprescs precisem uscir melhor todos os recurses tecnológieos à disposição parre se torncrem mais produtivas e sobreviverem a๑ novo cenário de negócios eada vez mais digitel.

Exigir mais produtividade não é algo relacionado ao conceito desgastado de "trabalhar mais", mas sim de "trabalhar melhor". Ou seja, as empresas que vão se destacar no mercado pós-pandemia são aquelas que conseguirem tirar do papel e acelerar de fato os projetos de transformação digital, usando a tecnologia para executar os processos com mais eficiência, agilidade, qualidade e inovação.

Nesse novo contexto de negócios mais produtivos, mais do que ter infraestrutura e equipamentos adequados, as empresas precisam ter sistemas que garantam a gestão otimizada de todos os seus processos e permitam planejar, antecipar e adaptar-se de forma rápida e eficiente. Ou seja, em um cenário virtual, no qual novas variáveis passam a ser relevantes para a gestão estratégica, é necessário ter o apoio de ferramentas que, de forma automatizada, monitorem as atividades em tempo real, forneçam os insights adequados para a tomada de decisão e ajudem a eliminar riscos e gargalos. 
Em um mundo no euel

sũo gercdos eered de 2,2

milhões de terchytes

todos os dicrs, segundo

estimativas do Garther, ter

ferromentas que ojudem

as empresers a tronsformar

essa dvellonche de

eódigos em informaçêes

mensuráveis, pelpáveis e

de fato relevantes parra os

negócios passa a ser uma

eondịç̃o de sobrevivêncị.

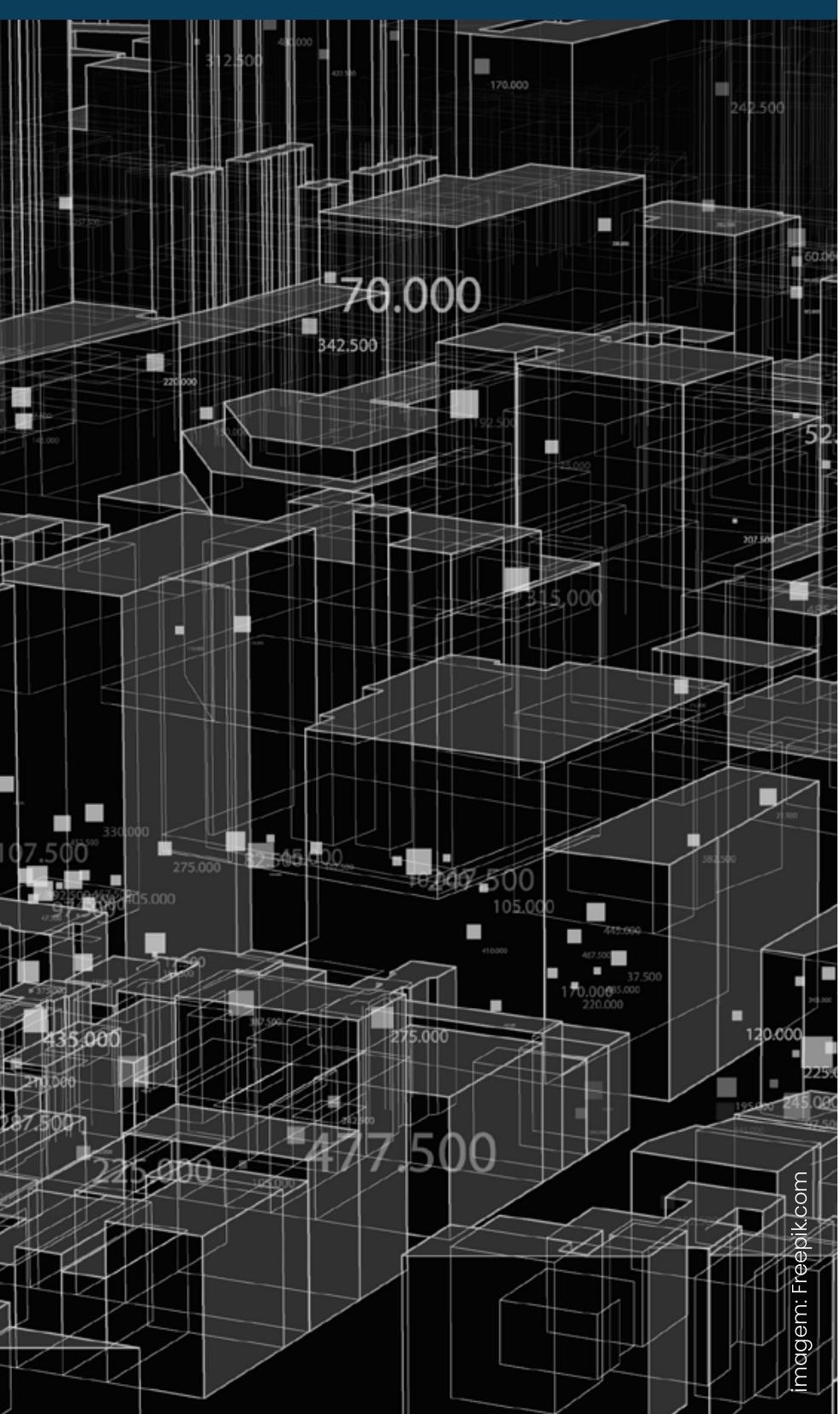

Quem tiver os melhores sistemas para extrair esses dados em tempo real e com custo acessivel garante vantagem competitiva nesse novo contexto.

Com isso, fica evidente que soluções de tecnologia deixam de ser um suporte e passam a ocupar um papel estratégico dentro das organizações, sendo peças-chave para garantir a automatização e simplificação de processos, acesso a serviços financeiros mais baratos e de melhor qualidade. Mas elas também são essenciais para entender e atender com mais assertividade as necessidades dos clientes.

O uso em larga escala da digitalização, da nuvem, da inteligência artificial, entre outras inovações, já está trazendo enormes ganhos a quem as utiliza. Com o aumento das relações e transações virtuais, as empresas precisam estar presentes de maneira integrada e em diferentes canais para se comunicar com clientes e atendêlos de forma simples, direta, personalizada e efetiva. Se essa estratégia estiver bem definida, com base em processos e boas soluções tecnológicas, a companhia certamente terá um bom ganho em produtividade e resultados positivos no final do mês, inclusive com aumento nos indicadores de satisfação dos clientes.

A produtividade empresarial já faz parte do core business das empresas, sendo quase que um pré-requisito para se destacar no futuro. Por isso, cabe aos gestores entender seu papel em melhorar o desempenho da companhia, buscando soluções e estratégias que viabilizem essa transformação.

Os desafiadores tempos que vivemos devem ser encarados como oportunidade para finalmente explorarmos todo o potencial da tecnologia. O mais importante é seguirmos assim: nos atualizando, aperfeiçoando e tomando novos rumos, conforme surjam os desafios. Afinal de contas, como brasileiros, somos especialistas em nos adaptar. 


\section{MAS, AFINAL, SOMOS OU NÃO PRODUTIVOS?}

Depois dessa reflexão, a pergunta que pode ficar é: como mensurar a produtividade do meu negócio? Essa é uma dúvida comum, mas a resposta não é tão difícil de se encontrar. Existem alguns indicadores de produtividade que devem ser vistos como parte da inteligência de negócios.

Talvez você já os conheça por nomes como KPIs ou indicadores-chave de performance. São métricas que buscam identificar avanços (ou retrocessos) pontuais em várias frentes do negócio e não apenas em relação aos resultados. Aplicadas no dia a dia operacional do negócio, servem como referência para que os colaboradores se esforcem para atingir os objetivos estratégicos da companhia.

Entre os principais indicadores, estão:

\section{A Qualidade:}

Indicadores que buscam avaliar o compliance em relação aos padrões de qualidade estabelecidos. Nesse caso, podem variar muito, identificando questões referentes à disponibilidade do serviço, aos prazos de entrega, ao número de reclamações, entre outros.

\section{A Capacidade:}

Neste caso, o indicador busca definir a entrega em uma lógica quantitativa, como o nível de produção em determinado período de tempo.

\section{A Competitividade:}

São indicadores que buscam medir métricas mais mercadológicas, que realmente indiquem o nível de competitividade da empresa no segmento em que atua. Um exemplo bem comum é o market share.

\section{O Turnover:}

A produtividade empresarial também tem a ver com a satisfação dos colaboradores. Por isso, o indicador de turnover é bastante utilizado.

Ele mede o nível de rotatividade na empresa e, quanto mais aprofundado for, mais evidente serão as chances de falhas internas, como no onboarding, na seleção de talentos ou mesmo no potencial da empresa em reter funcionários, por exemplo.

\section{A Lucratividade:}

Por fim, vale ressaltar que os indicadores de lucratividade continuam extremamente importantes. Eles servem para medir as entregas do time de vendas, indicando o ganho real da organização.

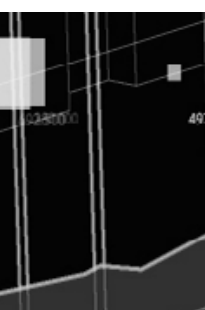




\section{O QUE PODEMOS FAZER NA PRÁTICA PARA PRODUZIR MELHOR?}

Existem algumas ações básicas que certamente irão ajudar a aplicar mudanças em prol da produtividade das organizações, em curto prazo. Abaixo, são listados sete itens que devem ser levados em consideração:

\section{Definir fluxos de trabalho}

Estabelecer uma sequência lógica e sistemática para a realização das atividades deve ser o primeiro passo do processo de estruturação. Isso busca evitar retrabalhos e torna o fluxo de entregas mais intuitivo e dinâmico. Assim, a "engrenagem gira" e seus setores não emperram as tarefas.

\section{Investir na capacitação do time}

O treinamento é essencial para que os colaboradores possam realizar suas entregas no nível esperado. Por isso, o investimento em treinamentos e em ferramentas deve ser feito de forma contínua.

\section{Estimular a comunicação interna}

Como um time pode produzir bem sem uma comunicação transparente, direta e sem ruídos? É importante investir em ferramentas que potencializem o trabalho em grupo, centralizando a comunicação como forma de melhorar e agilizar as entregas.

\section{Revisar processos}

Incluir a revisão de processos como uma etapa prática comum e obrigatória em seu planejamento é essencial. Ela deve acontecer sempre antes da implementação de alguma mudança bem como após sua execução. Trata-se de uma forma de potencializar o controle dos processos, além de evitar falhas.

\section{Definir metas e objetivos estratégicos}

Um bom planejamento é essencial para melhorar a produtividade empresarial. Por isso, procure criar um plano de ações que seja justo, mas ao mesmo tempo desafiador, com metas que realmente levem a empresa ao crescimento.

\section{Gerenciar o tempo}

O que seria de um time produtivo sem práticas inovadoras para melhorar sua gestão do tempo? Essa é uma forma de, em um ritmo contínuo, melhorar as entregas da empresa, estabelecendo metas e limites de tempo para cada tarefa a ser executada.

\section{Usar a tecnologia e as ferramentas adequadas}

A tecnologia é o ingrediente essencial deste processo, pois é ela o vetor que possibilita às organizações realmente se tornarem produtivas. Aqui, o ponto crucial é identificar no mercado os provedores que ofereçam as melhores ferramentas, sistemas e soluções para a companhia, trazendo a tecnologia para o core do negócio, potencializando suas operações.

Integração de dados, automação de processos, rapidez, segurança e escalabilidade são apenas alguns dentre tantos benefícios da adoção da tecnologia em prol da produtividade. 


\section{Enfim, o reecdoque deix॰ perre os}

gestores das emprescrs é: se apoiem na teenologid e busquem projetos de tronsformação digital com foco na produtividade. A eonstrução de um novo ẹpítulo na histórị alas emprescs bresileiras depende de edpacidede do mereado de adeptar-se a esse nove ecminho.

\section{Dennis Herszkowiez CEO Totvs}

Assumiu a presidência da TOTVS em novembro de 2018 para conduzir a estratégia de crescimento, operação, resultados e gestão de pessoas da companhia. Formado em Marketing pela Escola Superior de Propaganda e Marketing (ESPM), possui mais de 20 anos de experiência na área de tecnologia.

Durante 15 anos atuou na Linx como sócio e diretor estatutário, ocupando diferentes vice-presidências, além de ter sido membro do Conselho de Administração de 2011 a 2014. Encerrou suas atividades na empresa como VP Executivo de Novos Mercados, unidade de negócios focada no mercado de fintechs. Sua posição de maior longevidade dentro da companhia, entre 2012 e 2017, foi como CFO e diretor de Relações com Investidores, sendo responsável pelo IPO em 2013 e follow-on em 2016, além de 20 aquisições no período.

O executivo iniciou sua carreira como trainee na Credicard e chegou a fundar sua própria companhia na década de 1990. Foi diretor geral do DeRemate.com no Brasil, fundador e CEO da Gibraltar.com, além de passagens pela Unilever e Credicard S.A. É formado em Propaganda e Marketing pela ESPM. 